\title{
Characteristics of US Patients and Prescribers Using Hydroxychloroquine During the COVID-19 Pandemic
}

J Gen Intern Med 36(12):3918-2 1

DOI: $10.1007 / \mathrm{s} 11606-021-07144-2$

(C) Society of General Internal Medicine 2021

\begin{abstract}
A fter preliminary evidence from small, poorly controlled studies suggested a role for hydroxychloroquine in treating SARS-CoV-2 infection, Donald Trump and several celebrities in March 2020 promoted the drug on social media and other platforms. This resulted in a surge in prescriptions and shortages affecting patients who required the drug to treat rheumatoid arthritis or lupus. ${ }^{1-4}$ Under pressure from the Trump administration, the Food and Drug Administration (FDA) on March 28 issued an Emergency Use Authorization (EUA) for hydroxychloroquine to treat COVID-19. ${ }^{5}$ Adequate clinical trial data soon showed the drug was ineffective, and the FDA retracted its EUA on June 15, although President Trump continued to endorse the drug publicly. Little is known about the characteristics of patients and prescribers who used hydroxychloroquine during the COVID-19 pandemic.
\end{abstract}

\section{METHODS}

We used a national claims database of commercially insured and Medicare Advantage patients (Optum's deidentified Clinformatics Data Mart) to identify new hydroxychloroquine users with a preceding 180 -day period of continuous insurance enrollment and no prior hydroxychloroquine use, in the pre-pandemic period (January 1, 2018-March 12, 2020) compared to the pandemic period (March 13-December 31, 2020). We divided the pandemic into two periods - the initial surge in use (March 13-June 18) and the period after the FDA revoked its hydroxychloroquine EUA (June 19-December 31). For each new user, we measured patient and prescriber characteristics. The Mass General Brigham Institutional Review Board approved use of de-identified claims data for this study.

Received June 1, 2021

Accepted September 8, 2021

Published online September 24, 2021

\section{RESULTS}

We identified 91,006 new hydroxychloroquine users. Before the pandemic, most were $\geq 40$ years old $(86.8 \%)$, female $(82.1 \%)$, and white $(56.2 \%) ; 56.0 \%$ had a diagnosis of rheumatoid arthritis or lupus, and $98.5 \%$ received a supply of 28 or more tablets (Table 1). The prescriber was most often a rheumatologist $(49.9 \%)$ or primary care physician $(23.3 \%)$, and $73.1 \%$ were high-volume hydroxychloroquine prescribers.

During the first 3 months of the pandemic, the average number of weekly new hydroxychloroquine users increased 2.9 times, from 449.2 to 1302.1 , with the largest peak in use (>1500 new users/day) on March 19-20, immediately after President Trump's first promotion of the drug (Fig. 1). After that initial surge, use remained 1.7 times elevated above prepandemic levels (761.0 new users/week), with a smaller peak from July 28 to 29 (>230 new users/day), again following promotion of the drug by President Trump.

Hydroxychloroquine use increased more among men than women (6.1-fold vs 2.2-fold change in the first period), although the absolute increase in use was similar for men (442.8/week) and women (410.1/week). Asian Americans had the greatest increase in use (6.7-fold change) and Black Americans the smallest increase (2.1-fold change) during the first period. The greatest increase in use during the initial surge was in the Northeast (7.0-fold change), including New Jersey (10.3-fold), New York (9.4-fold), and Rhode Island (5.7-fold). After this initial surge, the greatest increase relative to pre-pandemic use was in the South (2.0-fold), including Arkansas (2.9-fold) and Tennessee (2.4-fold).

Among hydroxychloroquine prescribers, the largest increases were among clinicians with no prior documented hydroxychloroquine prescribing $2.3 \%$ of new users pre-pandemic vs. $51.4 \%$ during the first pandemic period, a 65-fold change), concentrated among nonrheumatology specialists (10.6-fold) and primary care physicians (4.8-fold). There was no increase in filled hydroxychloroquine prescriptions written by rheumatologists or previous high-volume hydroxychloroquine prescribers.

\section{DISCUSSION}

Among commercially insured and Medicare Advantage patients, weekly new users of hydroxychloroquine tripled during 
Table 1 New Hydroxychloroquine Users Before and During the COVID-19 Pandemic

\begin{tabular}{|c|c|c|c|c|c|}
\hline & \multicolumn{3}{|c|}{ Avg no. of new HCQ users per week (\%) ${ }^{\text {a }}$} & \multicolumn{2}{|c|}{ Fold change $^{b}$} \\
\hline & $\begin{array}{l}\text { Pre-pandemic } \\
\text { (Jan 1, 2018-Mar 12, } \\
\text { 2020) }\end{array}$ & $\begin{array}{l}\text { Pandemic period } 1 \text { (Mar 13, } \\
\text { 2020-Jun 18, 2020) }\end{array}$ & $\begin{array}{l}\text { Pandemic period } 2 \text { (June 19, } \\
2020-D e c 31,2020)\end{array}$ & $\begin{array}{l}\text { Period } \\
1\end{array}$ & $\begin{array}{l}\text { Period } \\
2\end{array}$ \\
\hline All patients & 449.2 & 1302.1 & 761.0 & 2.9 & 1.7 \\
\hline \multicolumn{6}{|l|}{ Age } \\
\hline$<18$ years & $3.5(0.8)$ & $14.1(1.1)$ & $5.1(0.7)$ & 4.0 & 1.4 \\
\hline $18-39$ years & $55.9(12.4)$ & $196.9(15.1)$ & $94.5(12.4)$ & 3.5 & 1.7 \\
\hline $40-65$ years & $198.5(44.2)$ & $573.4(44.0)$ & $326.2(42.9)$ & 2.9 & 1.6 \\
\hline $65+$ years & $191.3(42.6)$ & $517.6(39.8)$ & $335.2(44.1)$ & 2.7 & 1.8 \\
\hline \multicolumn{6}{|l|}{ Gender ${ }^{c}$} \\
\hline Men & $80.5(17.9)$ & $490.6(37.7)$ & $235.8(31.0)$ & 6.1 & 2.9 \\
\hline Women & $368.7(82.1)$ & $811.5(62.3)$ & $525.2(69.0)$ & 2.2 & 1.4 \\
\hline \multicolumn{6}{|l|}{ Race/Ethnicity } \\
\hline White & $252.3(56.2)$ & $647.2(49.7)$ & $393.8(51.7)$ & 2.6 & 1.6 \\
\hline Black & $50.8(11.3)$ & $107.0(8.2)$ & $60.0(7.9)$ & 2.1 & 1.2 \\
\hline Hispanic & $56.1(12.5)$ & $156.1(12.0)$ & $78.5(10.3)$ & 2.8 & 1.4 \\
\hline Asian & $13.1(2.9)$ & $87.4(6.7)$ & $18.3(2.4)$ & 6.7 & 1.4 \\
\hline Unknown & $76.9(17.1)$ & $304.3(23.4)$ & $210.5(27.7)$ & 4.0 & 2.7 \\
\hline \multicolumn{6}{|l|}{ Geographic region $^{\mathrm{d}}$} \\
\hline Northeast & $43.6(9.7)$ & $303.7(23.3)$ & $57.3(7.5)$ & 7.0 & 1.3 \\
\hline Midwest & $92.4(20.6)$ & $178.0(13.7)$ & $134.3(17.7)$ & 1.9 & 1.5 \\
\hline South & $222.9(49.6)$ & $597.1(45.9)$ & $444.9(58.5)$ & 2.7 & 2.0 \\
\hline \multirow{2}{*}{\multicolumn{6}{|c|}{ Insurance type }} \\
\hline & & & & & \\
\hline Commercial & $210.1(46.8)$ & $733.6(56.3)$ & $375.9(49.4)$ & 3.5 & 1.8 \\
\hline Medicare Advantage & $239.1(53.2)$ & $568.4(43.7)$ & $385.1(50.6)$ & 2.4 & 1.6 \\
\hline \multicolumn{6}{|c|}{ Diagnosis of rheumatoid arthritis or lupus } \\
\hline No & $197.8(44.0)$ & $1037.7(79.7)$ & $503.1(66.1)$ & 5.2 & 2.5 \\
\hline Yes & $251.4(56.0)$ & $264.4(20.3)$ & $257.9(33.9)$ & 1.1 & 1.0 \\
\hline \multicolumn{6}{|l|}{ Pharmacy type } \\
\hline Not mail-order & $34.9(7.8)$ & $43.1(3.3)$ & $33.3(4.4)$ & 1.2 & 1.0 \\
\hline Mail order & $414.4(92.2)$ & $1259.0(96.7)$ & $727.7(95.6)$ & 3.0 & 1.8 \\
\hline \multicolumn{6}{|l|}{ Prescription size } \\
\hline$<28$ tablets & $6.9(1.5)$ & $574.1(44.1)$ & $255.1(33.5)$ & 83.3 & 37.0 \\
\hline$\geq 28$ tablets & $442.3(98.5)$ & $728.0(55.9)$ & $505.9(66.5)$ & 1.6 & 1.1 \\
\hline \multicolumn{6}{|l|}{ Prescriber type ${ }^{e}$} \\
\hline Rheumatologist & $224.1(49.9)$ & $218.4(16.8)$ & $221.4(29.1)$ & 1.0 & 1.0 \\
\hline Primary care physician & $104.7(23.3)$ & $497.9(38.2)$ & $284.6(37.4)$ & 4.8 & 2.7 \\
\hline $\begin{array}{l}\text { Non-rheumatology physi- } \\
\text { cian specialists }\end{array}$ & $29.0(6.5)$ & $308.1(23.7)$ & $77.0(10.1)$ & 10.6 & 2.7 \\
\hline $\begin{array}{l}\text { Nurse practitioner or } \\
\text { physician assistant }\end{array}$ & $39.5(8.8)$ & $120.7(9.3)$ & $101.0(13.3)$ & 3.1 & 2.6 \\
\hline Other non-physician & $17.7(3.9)$ & $60.6(4.7)$ & $26.6(3.5)$ & 3.4 & 1.5 \\
\hline Unknown & $34.2(7.6)$ & $96.4(7.4)$ & $50.3(6.6)$ & 2.8 & 1.5 \\
\hline \multicolumn{6}{|c|}{ Prescriber's prior HCQ use ${ }^{f}$} \\
\hline Never prescriber & $10.3(2.3)$ & $668.6(51.4)$ & $253.4(33.3)$ & 64.6 & 24.5 \\
\hline $\begin{array}{l}\text { Low prescriber (1-100 } \\
\text { claims) }\end{array}$ & $76.3(17.0)$ & $208.9(16.0)$ & $139.1(18.3)$ & 2.7 & 1.8 \\
\hline High prescriber $(>100$ & $328.4(73.1)$ & $328.2(25.2)$ & $318.2(41.8)$ & 1.0 & 1.0 \\
\hline $\begin{array}{l}\text { claims) } \\
\text { Unknown }\end{array}$ & $34.2(7.6)$ & $96.4(7.4)$ & $50.3(6.6)$ & 2.8 & 1.5 \\
\hline
\end{tabular}

${ }^{a}$ Weekly averages calculated as the number of new users divided by the number of weeks in the time period (114.6 weeks pre-pandemic, 14 weeks in pandemic period 1, and 28 weeks in pandemic period 2)

${ }^{b}$ Fold change was calculated as the average number of weekly new users in each pandemic period, divided by the pre-pandemic average number of weekly new users

${ }^{c}$ Excludes 3 individuals with unknown gender

${ }^{d}$ Excludes 128 individuals who did not live in the US states (e.g., Puerto Rico)

${ }^{e}$ Prescriber type was defined based on the primary National Uniform Claim Committee Health Care Provider Taxonomy code associated with the National Provider Identifier listed on the prescription claim. Physician specialists included all specialties except rheumatology. The most common specialties, in descending order based on number of new hydroxychloroquine users, were dermatology, emergency medicine, obstetrics and gynecology, allergy and immunology, and cardiology. Clinical nurse specialists were included along with nurse practitioners and physician assistants. The most common other non-physician prescribers included students, nurses, dentists, homeopathic providers, podiatrists, chiropractors, emergency medical technicians, optometrists, midwifes, and behavioral health clinicians

${ }^{f}$ Prescriber prior hydroxychloroquine use was defined as the number of filled hydroxychloroquine prescriptions written by the same individual prescriber for any patient in the Optum dataset from January 2004 through the beginning of the pandemic on March 12, 2020, excluding the index filled prescription; If the index hydroxychloroquine prescription was not linked to an individual prescriber (e.g., hospital or practice-level National Provider Identifier codes), prior use was recorded as unknown

HCQ hydroxychloroquine 




Fig. 1 New hydroxychloroquine users, January-December 2020. Each bar shows the number of new hydroxychloroquine users each week, from January 3 to December 31, 2020. The black dashed line shows the average number of weekly new users in the pre-pandemic period (January 1, 2018-March 12, 2020). The gray dotted line shows the number of new COVID-19 cases in the USA each week reported by the US Centers for Disease Control and Prevention (https://covid.cdc.gov/covid-data-tracker/\#trends_dailytrendscases, Accessed July 20, 2021). The individual prescriber for each filled prescription was stratified based on the number of filled hydroxychloroquine prescriptions written by the same individual prescriber for any patient in the Optum dataset from January 2004 through the beginning of the pandemic (March 12, 2020).

If the index hydroxychloroquine prescription was not linked to an individual prescriber (e.g., hospital or practice-level National Provider Identifier codes), prior use was recorded as unknown. AHA, American Heart Association; HCQ, hydroxychloroquine; JAMA, Journal of the American Medical Association; NEJM, New England Journal of Medicine

the early surge in the COVID-19 pandemic, with the greatest increases prescribed by non-rheumatologist physician specialists and primary care physicians with no prior experience prescribing the drug.

While studies have documented a peak in hydroxychloroquine use during March 2020, ${ }^{2,3}$ we also found that hydroxychloroquine use remained elevated above pre-pandemic levels from July through December 2020, even after the FDA withdrew the drug's EUA and evidence emerged about its lack of efficacy. ${ }^{6}$ We observed increased use in the days following President Trump's public promotion of the drug in March and July 2020, although proving causation is complicated by multiple competing news events.

Exhortations by public figures and politically driven regulatory decisions during the pandemic had important and sustained effects on use of hydroxychloroquine, exposing thousands of patients to a drug with no benefit and documented risks, as well as creating shortages for patients with rheumatoid arthritis or lupus who depended on the drug. ${ }^{4}$ Federal policymakers and regulators should learn from this failed experience to reduce misinformation and promote better evidence-based prescribing in the future.

Benjamin N. Rome, $M D, M P H^{1}$

Jerry Avorn, $M D^{1}$

Aaron S. Kesselheim, MD, JD, MPH ${ }^{1}$

${ }^{1}$ Program On Regulation, Therapeutics, And Law (PORTAL), Division of Pharmacoepidemiology and Pharmacoeconomics, Department of Medicine, Brigham and Women's Hospital and Harvard Medical School,

1620 Tremont Street, Suite 3030, Boston, MA 02120 , USA

Corresponding Author: Benjamin N. Rome, MD, MPH; Program On Regulation, Therapeutics, And Law (PORTAL), Division of Pharmacoepidemiology and Pharmacoeconomics, Department of Medicine, Brigham and Women's Hospital and Harvard Medical School, 1620 Tremont Street, Suite 3030, Boston, MA 02120, USA (e-mail: brome@bwh.harvard.edu). 
Funding This work was funded by a grant from Arnold Ventures.

\section{REFERENCES}

1. Liu M, Caputi TL, Dredze M, Kesselheim AS, Ayers JW. Internet Searches for Unproven COVID-19 Therapies in the United States. JAMA Internal Medicine. 2020;78:29-31. https://doi.org/10.1001/ jamainternmed.2020.1764

2. Vaduganathan M, van Meijgaard J, Mehra MR, Joseph J, O'Donnell CJ, Warraich HJ. Prescription Fill Patterns for Commonly Used Drugs During the COVID-19 Pandemic in the United States. JAMA. 2020;323(24):2524. https://doi.org/10.1001/jama.2020.9184

3. Bull-Otterson L, Gray EB, Budnitz DS, et al. Hydroxychloroquine and Chloroquine Prescribing Patterns by Provider Specialty Following Initial Reports of Potential Benefit for COVID-19 Treatment - United States,
January-June 2020. MMWR Morbidity and Mortality Weekly Report. 2020;69(35):1210-1215. https://doi.org/10.15585/mmwr.mm6935a4

4. Rome BN, Avorn J. Drug Evaluation During the COVID-19 Pandemic. New England Journal of Medicine. 2020;382(24):2282-2284. https://doi. org/10.1056/NEJMp2009457

5. Shear MD, Haberman M. Health Dept. Official Says Doubts on Hydroxychloroquine Led to His Ouster. New York Times. April 22, 2020. Accessed July 1, 2021.https://www.nytimes.com/2020/04/22/us/politics/rick-bright-trump-hydroxychloroquine-coronavirus.html.

6. Boulware DR, Pullen MF, Bangdiwala AS, et al. A Randomized Trial of Hydroxychloroquine as Postexposure Prophylaxis for COVID-19. New England Journal of Medicine. 2020;383(6):517-525. https://doi.org/10. $1056 /$ nejmoa2 ${ }^{\prime} 6638$

Publisher's Note: Springer Nature remains neutral with regard to jurisdictional claims in published maps and institutional affiliations. 